Article

\title{
Context-Based Interpretation of Subordinating Conjunctions in Communication
}

\author{
Aziz Thabit Saeed ${ }^{1, *(1)}$ and Saleh Al-Salman ${ }^{2}$ \\ 1 Faculty of Language Studies, Arab Open University-HQ, Al-Ardiya 92400, Kuwait \\ 2 Department of English Language and Translation, Applied Science Private University, \\ Amman 11931, Jordan; salehalsalman2000@gmail.com \\ * Correspondence: aziz_sanaa@hotmail.com
}

Received: 6 October 2019; Accepted: 20 January 2020; Published: 16 November 2020

check for updates

\begin{abstract}
While acknowledging that different conjunctions define different relationships between ideas, this study focuses on the interpretation of four subordinating conjunctions, namely, because, since, for and as in causal clauses. Since the meanings of these conjunctions vary according to context, among other things, they usually pose problems to language users leading to misinterpretations. Not only does this emerge from the fine and minute distinctions in usage between them, but also due to the lack of adequate knowledge of the rules of language use in their metatheoretical framework. This kind of knowledge is crucial in interactive communication, speech acts, pragmatics, logical arguments and multidisciplinary debates. The data for this study were compiled from grammar books, articles, and from the British National Corpus (BNC). The data were analyzed not only to identify the discrete features of each conjunction that would render it different from its synonymous counterparts, but also to understand the kind of knowledge required to determine the choice. The findings of the study reveal that, in addition to the syntactic constraints, the degree of the 'givenness' or 'newness' of the information that the conjunction introduces, context, degree of formality of the register, and lexical density of the utterance that contains the conjunctions emerged to play a role.
\end{abstract}

Keywords: subordinating conjunctions; context; synonyms; discourse

\section{Introduction}

Subordinating conjunctions are defined as function words that show "the connection of meaning between the main clause and the subordinate clause" (Biber et al. 2002, p. 31). They fall under different categories according to the functions they perform and the relationships they establish between sentential elements. Besides their function as a transitional link between two propositions in the sentence, denoting time, place, cause, and effect, they equally signal logical relationships between referring expressions, referents, and meaning. Therefore, the interpretation of subordinating conjunctions should be perceived from both linguistic and paralinguistic perspectives.

Causal clauses together with their subordinating conjunctions comprise two sentential elements signaling cause and effect, as in the following examples:

(1) I stayed home today because I am not feeling well;

(2) As the weather was nice, we decided to go jogging;

(3) Since you did not work hard enough for the test, your grades were below average;

(4) John was taken to the hospital for he has a severe migraine headache.

An interesting observation that these examples reveal is that the subordinating connecting words convey more or less the same meaning, i.e., they are synonymous. This kind of synonymy renders such 
grammatical expressions problematic for EFL learners, who wonder whether it makes any difference to use because, for, since or as in each one of these instances. Consider:

(5) He ate four sandwiches because/since/for/as he was very hungry.

Definitely, a sentence like this will add to the bewilderment of the EFL learner, for the four conjunctions can be acceptable with various degrees: none is inaccurate. Only through an extended context can one of them become more preferable or completely unacceptable. In semantics, the overall meaning is not associated with words only, but extends to sentences as well. That is why we refer to different types of meaning, including speaker's meaning (intended meaning), and hearer's meaning (interpreted meaning). In such cases, the right choice of conjunction may be best determined through invoking additional elements related to context, collocational restrictions, connotational definition, speaker's intention, hearer's reaction, etc. This is based on the language user's knowledge of the rules of proper usage. In an article that addresses the effects of context on utterance, Sinclair (1992) maintains:

It is widely accepted that non-linguistic factors in the form of context play an important role in the bridging of the gap between the linguistic meaning of an utterance and the meaning which a communicator intends to convey with this utterance. In addition to the term "context", there are several other terms used in the literature to refer to the non-linguistic factor(s) involved in determining utterance interpretation. These include, inter alia, "contextual knowledge", "background knowledge", and "world knowledge" (p. 106).

Synonymous words such as subordinating conjunctions, may lead to inappropriate use by non-native speakers of the language due to source language (SL) interference. While this claim is valid to a large extent, sound knowledge of the rules of language use, discourse functions, conversational maxims, formal principles of logic and reasoning, etc., are central elements to grasping meaning in spoken and written discourse. According to Hurford et al. (2007, p. 26), "in talking about 'sense', we deal with relationships inside the language, but in talking about reference we deal with the relationship between language and the world."

The intricacies associated with the subject of synonymy and the challenge it poses for EFL learners have been discussed in many studies, including Saeed (2014), Saeed and Fareh (2006) and Wang (2009), among others. These studies focused on lexical synonymous expressions. Saeed (2014) investigated the subtle considerations that govern the use of four synonymous verbs: cease, end, finish and stop, in light of context. The findings of the study "reveal many distinctive features that characterize each. These features include completeness vs. incompleteness, finality vs. temporariness and abruptness vs. gradualness" (117). Saeed and Fareh (2006) investigated the semantic and syntactic considerations that "govern the use of the verbs steal, rob and burglarize in authentic contexts." Some of the distinguishing features that govern the use of such verbs included "location of activity, object of activity, and manner of action" (323).

Although studies that have explored the differences in the meaning and use of synonymous lexical items are many, not as many studies have been conducted to investigate the subtle determining features that govern the use of certain synonymous grammatical expressions. One of the few studies on such topics is that of Riddle (1989), who studied the semantic differences in the use of three synonymous transition expressions that tend to pose problems for EFL learners, namely however, nevertheless, and in spite of. Her analysis showed "how a detailed lexical semantic analysis of such highly utilized synonymous transitions could help EFL learners decipher their various meaning and range of uses" (see Saeed 2014, p. 102).

Among the few studies that have focused on the subject of causal markers are Ford and Mori (1993), Meier (2001), Mulkar-Mehta et al. (2011), Povolná (2012) and Mo (2015). In their study, entitled 'Causal Markers in Japanese and English Conversations: A Cross-linguistic Study of Interactional Grammar,' Ford and Mori (1993) investigated the use of causal connectors in managing disagreement between English and Japanese, which exhibit different sentence structures of (SVO) and (SOV), respectively. 
The researchers concluded that the use of causal connectors in English and Japanese "supports the hypothesis that there are needs and constraints in human interaction that affect the shape of turns and the use of grammar in typologically distinct languages" (p. 58). Research findings of this nature are consistent with the opinions held by the authors of this piece of research, who subscribe to the thesis that more interdisciplinary and cross-linguistic research and typology is key to arriving to conclusive evidence on the interpretation of causal markers and subordinating conjunctions per se. Our current study is merely a prelude.

Another contrastively oriented study was contributed by Meier (2001) who compared and contrasted causal linkage in English and Norwegian. The study focused on the correspondence between English causal subordinators and their counterparts in Norwegian in the event of translation from one language into the other. Emphasis was placed on the "distributional, pragmatic and semantic factors that determine the choice of correspondence in the target language. The findings suggested that the causal relation is more often explicitly lexicalised in English than in Norwegian" (4).

Mulkar-Mehta et al. (2011), in their study titled, "Causal Markers across Domains and Genres of Discourse," touched upon the importance of the phenomenon of causality in discourse and its relevance to Natural Language Processing (NLP). The study discussed the use of causal markers to signal and determine causal relationships in particular domains or genres. The researchers investigated the nature and importance of this relationship and the extent to which the use of causal markers is an inherently domain-dependent or genre-dependent discourse. Their findings revealed that "causal markers, especially causatives (causal verbs) are extremely domain dependent, and moderately genre dependent." However, a complete picture of this relationship requires a more comprehensive and interdisciplinary research to investigate the extent to which this particular relationship is domain-dependent.

Povolná (2012) investigated the most prominent discourse markers used by MA level Czech when expressing causal and contrastive relations. Povolná's investigation has illustrated that "expressing causal and contrastive relationships between adjacent or more distant segments of discourse is especially important in academic prose, ... where authors/writers consider it of great importance to organize their discourses in harmony with their communicative intentions and expect their reader(s) to interpret the message accordingly" (Povolná 2012, pp. 145-46). This lends support to the active role of the interlocutors, their intentions, and their compliance with conversational maxims when communicating with their audience/readers.

The use of causal connectives by native speakers and foreign language learners was the topic of a study conducted by Mo (2015). Mo compared "the Chinese learners' use of causal connectives and that of English native speakers by a corpus-based approach" (2426). The results showed that Chinese learners reflected higher density in their use of causal connectives compared to native speakers, but their variety is smaller. In addition, while Chinese learners put adverbial connectives in a sentence's initial position, native speakers of English place them medially.

While the studies reviewed above show how EFL learners from different languages use such markers, how such markers are used in discourse, etc., other studies have focused on the pragmatic functions of these conjunctions as cohesive devices, including Blackburn (2017) which echoes the intimate relationship between meaning and an understanding of the philosophy of language in a multi-disciplinary context. Subjects pertaining to philosophy of language include the study of composition, semantics and logic, reference, and much more." To this end, this study lends support to the thesis that interactive and meaningful communication is innately related to the semantic tringle of concept, representation, and referent. Therefore, it is not only words per se that have meaning, but also language users have a fundamental role to play based on their knowledge of the world, along with their intention and attitudes. It is the nature of meaning and how it refers to the real world that the present study aims to depict. 


\section{Objective of the paper:}

This paper explores the salient uses of the four conjunctions, because, as, for and since, in light of syntactic, semantic, and contextual considerations.

More specifically, the paper attempts to answer the following questions:

(a) Are the synonymous causal subordinating conjunctions: because, since, for and as interchangeable?;

(b) What are the prominent uses that characterize each one of the four conjunctions and therefore make it different from the others?;

(c) To what extent can context highlight the uses of these conjunctions?

The study is significant as it investigates the factors, both theoretical and metatheoretical, that determine the uses of highly important synonymous conjunctions, which surface in virtually all forms of interactive communication. Of all language users, EFL learners encounter difficulties in this particular domain of language use. Other important domains, in which careful use of these conjunctions plays a significant role in communication, include translation, logical debates, and speech acts of different genres. In translation, for instance, rendering a target language equivalent may be largely affected if synonymous subordinating conjunctions are semantically or contextually confused.

To the extent that this study addresses a teaching-learning concern, namely the interpretation of subordinating conjunctions in communication, it clearly concerns itself with language in education, especially advanced English as a second/foreign language. The students' ability to correctly use subordinating conjunctions in real-life communicative situations-in speech and writing-will help improve the language proficiency of ESL/EFL learners, since it has practical applications in teaching and pedagogy.

Research in the area of synonymous conjunctions and the principles that govern the use of such synonyms is relatively scanty; to the best knowledge of the authors, only modest research attempts have been made to explore this very important area of language use.

More succinctly, this article sets to explicate the range of reasons that may be responsible for the slight differences in meaning and/or context of the four subordinating conjunctions in question. Applying such a holistic approach, which takes into consideration aspects of grammar, semantics, formality, pragmatics, etc., is both relevant and sound.

\section{Research Methodology}

\subsection{Data Collection}

In order to identify the semantic, syntactic and contextual constraints that differentiate these conjunctions from one another, it was necessary to examine and analyze how they are actually used in various authentic contexts. Therefore, the data on which the analysis was based were culled from grammar books, articles, and from the British National Corpus (British National Corpus 2000), whose data are meant to be representative of contemporary English language use in both written and spoken registers, and which come from different genres and different disciplines. Most of the data were culled from BNC with a few examples, less than $5 \%$ of the data, collected from electronic websites, grammar books, dictionaries, articles, handouts, grammar exams, most of which were UK (British English)-based materials which target learners of English as a foreign language, representing senior-level (4th year) university students in English Language and Literature programmes.

The data mining process from the BNC was not as straightforward for the words as, for and since. When entering each word into the BNC search, the authors had to read more than one thousand instances for each of these words, since such words have multiple meanings other than the causal one, which is the focus of our current study. For instance, in some cases a random sample of $100 \mathrm{BNC}$ examples can show as few as five examples, and sometimes fewer, of the word for as a causal linking word. Even when using the pos-tag feature, we still got many non-causative uses when searching for as, for and since. For instance, the part of speech that a causative marker should have is a conjunction, and 
in entering this specification, we still were encountered with thousands of examples, since these words exhibit many different uses as conjunctions, i.e., being a conjunction does not mean the word is used as a causative maker only. Webster's Dictionary, for example, lists eight different uses for the word as when used as a conjunction, one of which is a causative marker ${ }^{1}$.

In a few examples, we attempted to modify the wording of the original to make the example shorter or clearer, while retaining the same structure and meaning. For instance, in the BNC example, which reads: "Alison (PS147). [901] Why? Bob (PS149). [902] Because I'll still be covering for John." It was slightly modified to look as follows:
A: Why?
B: Because I'll still be covering for John. (BNC)

\subsection{Data Analysis}

The authors followed the iterative approach when compiling and analyzing the data, in which the culled data of contextualized examples were increased repeatedly until the authors were fully convinced that a larger corpus of data will not affect the categorization process. They first piloted by analyzing 50 examples for each causative marker, i.e., analyzing a set of data that was composed of 200 contextualized examples for the four causative conjunctions in the study. Analyzing this first set of data pointed to certain determining elements that helped the authors decipher contextual elements that motivated the use of one rather than its synonymous counterparts. Then it was decided to extend the data to see if the judgments the authors had already made could be supported and to see if the extended data would reveal other elements that govern the use of these linkers. Thus, the sample was widened by 80 examples, 20 for each subordinating maker. This additional set of data did reveal more points that were relevant and enabled the authors to make more generalizations. The contribution of the second set to building up the authors' main arguments motivated them to widen the set of data further, by adding 20 more contextualized examples for each subordinating marker in the study. Again, this time the authors found more governing causes that determine the use of one causative conjunction rather than its synonyms, but not as many as the previous two sets had revealed. Finally, it was thought it would be wise to add one final set of examples to the existing pool, so as to have the final set of data comprise 100 contextualized examples for each causative marker. The authors scrutinized the last portion of added data and found very little that could add to the generalizations that they had already formulated. Thus, it was decided that 400 contextualized examples were a reasonable set of data.

Of course, we cannot negate the possibility that a larger set of data could reveal more determining elements that govern the use of these synonymous linkers; nevertheless, it is not expected that the findings will differ substantially.

In analyzing the data, the authors did not merely rely on the examples and the brief context that they exhibit, but in very many cases, they scrutinized the wider context of each example by referring to the original source of the examples, which was easily obtainable through BNC. This was important for identifying the syntactic, semantic, and/or pragmatic features that contribute to legitimizing the use of one causative marker rather than its synonymous counterparts. After completing the analysis, the authors discussed their judgements with two native English speaker language specialists for verification and crosschecking.

1 Available online: https://www.merriam-webster.com/dictionary/as (accessed on 15 August 2019). 


\section{Findings and Discussion}

\subsection{Non-Causal Uses}

The corpus of data analyzed was indicative as to how, where and when each of the four subordinating conjunctions in question (because, since, for, and as) occurs. The findings were based on the observed constraints governing the occurrence of these conjunctions. However, it is expedient before embarking on the analysis to mention the fact that the vast majority of uses of as, for, and since tend to be non-causal. Syntactically speaking, since, for, and as, may have a different word class membership depending on the type of relationship they establish between clauses. For example, since is a preposition or adverb when it refers to time, but it is a conjunction when it denotes cause. As and since are prepositions or adverbs when they express time, but both are conjunctions when they express cause $^{2}$. Consider the following examples:

(6) It is interesting that as computers get more powerful, they also get smaller. [Adverb].

(7) As Socrates so philosophically put it, since we don't know what death is, it is illogical to fear it. [Conjunction]. (BNC)

In these two examples, while as in (6) conveys a temporal value, since in (7) conveys a causative sense. Each one of the conjunctions targeted in this study, except for because, assumes a number of functions besides the causal one. These functions vary according to a number of variables invoking syntactic, semantic, pragmatic and cognitive constraints, which contribute to interpreting meaning. In other words, the interpretation of meaning is linked to an understanding of the philosophy of language where matters of meaning, reference and the world come into play (Blackburn 2017).

Collins Cobuild York English Usage (Sinclair 1990) offers a brief discussion of each of the four linkers in the study. For example, it presents the following when explaining the uses of as:

(a) "Used in time clauses." Example: "She wept bitterly as she told the story."

(b) "Used to mean because." Example: "She bought herself an iron as she felt she couldn't keep borrowing Ann's."

(c) "Used with adjectives." Example: "She regarded them as snobbish."

(d) "Used in prepositional phrases." Example: "He was regarded as something of a troublemaker."

(e) "Used in comparison." Example: "He looked over his shoulder as jack had done." (Collins Cobuild York English Usage) (Sinclair 1990, pp. 66-67).

This source offers similar examples for the uses of for and since (see pp. 258-59 and 620-30). However, such a treatment, though it lists examples of the uses, does not say much about what differentiates these synonymous markers from each other or from because when used as causatives.

Although some dictionaries and grammar books offer treatment of the four makers in the study, such treatment falls short of providing an in-depth analysis of the contextual (meta-theoretical, pragmatic, and knowledge-related) factors that normally determine the choice of one marker rather than its synonymous counterparts. In what follows, we will attempt a brief discussion in this direction.

\subsection{Simultaneous Usage: Causal and Non-Causal}

In some cases, as and since may swing between the causal and temporal meanings to allow for contextual or pragmatic interpretations, as the following examples show:

(8) Since Reagan became president, the Soviets have come to the bargaining table ${ }^{3}$

2 Available online: http://www.sjsu.edu/writingcenter/handouts/Subordinating\%20Conjunctions.pdf (accessed on 20 August 2019).

3 Available online: Good, Ed. 'Grammar Tips and Articles.' https://www.grammar.com/as-because-since-for/ (accessed on 10 September 2019). 
(9) As Ted's star began to wane, John became the palace's leading scorer ... . (BNC)

Here, the meaning of the conjunctions as and since may be one of cause/reason or one of time, depending on the reader's orientation and judgment. It is the reader's background, orientation, and attitude towards the proposition, the concept, its representation, and the referent in the real world, which determine the final choice.

The following is another example which shows that the use of since can be ambiguous, as it can indicate a reason, or it can be a time indicator.

(10) I have been eating well since I started exercising regularly.

In this example, two meanings are being expressed: the first meaning is based on a causal interpretation that 'exercising regularly has made me eat well,' and the second meaning: "I have been eating well since the day I started exercising," is based on temporal considerations. The sense that the subordinator conveys depends on the perspective of the interlocutor(s) and with the wider context. The same is true with as, as in the following example:

(11) His wife started crying like a child as they were leaving the country they had loved. (Item from an exam).

In Example (11), as can indicate both a temporal relationship (i.e., while), or a causal one (i.e., because).

However, in Example (12), below, as conveys a temporal sense:

(12) As the music and dialogue of the offstage begin, a member of "Pamela" cast turns the volume off. (BNC)

However, modifying the structure of the utterance can result in a meaning change. For instance, if we change the tense of the verb, say to the past tense, we have two readings: a temporal and a causal one. Consider:

(13) As the music and dialogue of the offstage began, a member of "Pamela" cast turned the volume off.

This example indicates that the use of $\underline{a s}$ as a causal marker can have a covert temporality sense, i.e., reflecting its major intrinsic role. The following example can illustrate this point further:

(14) I was interested in how many of us went back to carrying car stock. Practically, every Century Hutchinson rep in London had a van full of books, while the Faber reps had to share one van between serval territories. So did the Biking Penguin reps, and it was a stricken van, too, as one of the reps had scraped off the rear bumper. (BNC)

Scraping the rear bumper was not a one-shot action, but rather something that predictably took time. Hence, the use of $a$ s tends to be more felicitous here than because.

Examples 8-14 above show that the use and interpretation of the subordinating conjunctions since and as is not based on purely theoretical knowledge of meaning, which could be both causal and temporal. It requires additional knowledge of the context and logical relations that will help disambiguate the situation, leading to a clearer understanding of the senses expressed in the above-mentioned propositions.

\subsection{Causal Uses}

Based on the above discussion, our data reveal that the non-causative uses of as, for and since are far more frequent than the causative ones. Only in some contexts, as the corpus in the study reveals, do these three markers convey causative senses like because. Yet, even when they assume the function of because, i.e., conveying causation sense, they are not always interchangeable. Total synonymy is virtually impossible in any pair of synonyms, an agreed upon principle in semantics. 
Lyons (1981, p. 148) argues, "Complete synonymy is rare, and absolute synonymy hardly exists" (see also Saeed and Fareh 2006; Saeed 2014), and our current study lends further support to this principle, as we shall see below.

In his article 'Looking for the causal values of as and since in large corpora, and how these values compare with each other,' Guillaume $(2018$, p. 1) argues that "it is not always easy to differentiate between since and as on a semantic level." For instance, in the following example, taken from the British National Corpus (British National Corpus 2000):

- A cloud chamber is good for detecting low energy, electrically charged particles as they leave behind a trail of liquid drops as they pass through the mist in the chamber.

Guillaume explains that "replacing as by since, or the opposite, can hardly be said to alter the original meaning of the sentences in question in any perceptible way" (ibid). Such a confirmation lends support to and is consistent with our initial hypothesis that the four causal subordinating conjunctions 'because', 'for', 'since' and 'as' convey more or less the same meaning, i.e., they are synonymous. This kind of synonymy renders such grammatical expressions problematic for EFL learners. Only though ample context can it be possible to decipher subtle nuances that differentiate one from its three synonymous counterparts.

In what follows, the prominent principles that our data reveal-governing the use of one causative maker as opposed to its synonymous counterparts—will be highlighted.

\subsubsection{Old vs. New Information}

In some cases, the choice between because and its synonyms can be determined by the importance of the cause or reason. In the examples that our data reveal, we found that since and as tend to be used very often when they introduce a reason that is considered a known piece of information. The following are examples:

(15) Since he is moody, he becomes unpredictable ${ }^{4}$.

Here, the conjunction since introduces a reason that makes the person unpredictable- - 'he is moody,'-which may discourage people from trying to be friends with him. Since this reason is known to people, the use of since rather than because is fitting, as it introduces something that is fairly known. However, if the reason is an important piece of information or information that is stressed, because will be more fitting, as in the following example:

(16) A: Where is Tom? He is supposed to be here by now.

B: He has just called. He won't be able to come because/? since/? as his car won't start. (Item from an exam)

In this example, neither since nor as is as fitting as because, since the reason for his (Tom's) not being able to come is the most important piece of information. That is, although the new piece of information is "he won't be able to come," the reason for not being able to come (i.e., 'his car won't start') is as important for his employer. Therefore, because is the most fitting.

The following is another example:

(17) ... according to Food Giant, is that everything is a lot cheaper. Since Food Giants are spreading so fast around the country-they've opened more than ... (BNC).

In this example, there has been previous information about the spread of Food Giant, so since introduces this known reason, and the result is opening more branches. The following extended context of this instance supports our point.

4 Available online: https://play.google.com/store/apps/details?id=com.quora.android\&hl=en_US\&gl=US (accessed on 15 August 2020). 
(18) But none of them [have] really rattled the big chains until Food Giant came along. It doesn't look much like a traditional Sainsbury's or Tesco's, with its warehouse-style shelves and handwritten signs. But it's the same size. And unlike the other discount stores, it has all the normal branded products, AND own-label groceries through Gateway, AND a full range of fresh foods, fruit, veg, and meat, just like its big rivals. The difference, according to Food Giant, is that everything is a lot cheaper. Since Food Giants are spreading so fast around the country-they've opened more than one store a month since they started last year-we've put their claims to the test. We chose a shopping basket of 29 items to compare them with Tesco and Sainsbury. (BNC)

The information that precedes the use of since relates to the nature, size, products and reasonable prices of the company. Knowing this information about Food Giant, the reader will not be surprised that such a company will spread fast and open more and more stores. Therefore, this expected cause and effect information is appropriately introduced by since.

The previous examples, 15-18, reveal that, despite the seemingly synonymous nature of the three subordinating conjunctions because, since and as, in actual usage they are not interchangeable. It is the nature and kind of information provided in each case that determines the choice. In other words, a more meticulous knowledge of the cause-effect relationships-based on logic and reasoning-would make the choice of one conjunction more fitting than others in a given situation.

The following example shows that the reason that since introduces may not be a very important piece of information for someone who is not well-acquainted with the Spanish culture, when in fact it is. Consider:

(19) Sunday mornings at Montserrat are a real treat, since the religious services are a celebration of Spanish culture. While drinking our essential morning tea and coffee we were lost in a sea of women in traditional dress with castanets. (BNC)

Since is used more fittingly than its synonymous counterparts when the cause and effect it connects is based on previously given information, and thus what it introduces does not constitute brand new information (see Prince 1981 and Saeed 2004 for more about the concepts of givenness and newness). Consider the following example:

(20) The idea here is consciously to replace the thoughts that trigger an unproductive feeling with other ones that do not. Since a feeling is always heralded by a thought, and since we have the ability to control our thoughts, then thinking offers the best hope for the prevention of unproductive feelings. (BNC)

In this example, the topic 'thoughts' has been introduced to the reader and, for smooth topic continuity, we expect more information about thoughts and what they generate. Since this information is related to what has been mentioned in the previous example, there is nothing absolutely new, therefore, since is a better choice than because, which usually gives importance to the reason it introduces. Of course, for is not appropriate syntactically in the beginning, as discussed above. As is not as appropriate as since because it assumes more familiarity with the topic than since. In other words, to use $a s$ in place of because, the reason needs to be something really known, more so than is the case with since. Consider the following example:

(21) It is a difficult situation for Garber to be in, since/as? he is not qualified for the job of negotiating with hostage takers ${ }^{5}$.

In this example, there is a feeling that the credentials of the applicant have been discussed and it was found that he is not suitable for the job. Thus, the use of since is justified, i.e., introducing a known

5 Available online: D'Silva, Elvis. Take This Train. https://www.rediff.com/movies/review/review-the-taking-of-pelham/ 20090827.htm (accessed on 2 August 2019). 
reason. The use of $a$ s is questionable, though, since-for $a s$ to be acceptable here-we expect the event to have been discussed before and to now be past news. Consider:

(22) Letter, C.R. Carter to President Gordon thanking him for his invitation to come to the college but declining it as he is not sure whether the 'whole hive' will look upon him favorably. (BNC)

In this case, we feel that the speaker is narrating a story, and indeed, Example (22) is a story item in a newspaper. Carter received an invitation, thought about it for some time and possibly discussed it with his associates, and finally took a decision to decline the invitation.

In addition, the causal as is felt to be more fitting than its synonymous counterparts when it narrates or states a factual piece of information, as in the following example:

(23) The nose-tingling aroma of rosemary in itself is enough to banish catarrh and sinus infections as it tickles coolly up into the nasal cavities and spreads behind the cheekbone and forehead. (BNC)

In this instance, readers are informed of what causes or leads to 'catarrh and sinus infections,' a fact (a reason) that is known to medical specialists, which means the reason is not something new, but rather a usual consequence of certain medical symptoms.

In the following example, neither since nor as is very fitting, given the important information the reason clause presents.

(24) He studied all night because/since?/for?/as* he had a difficult test the next day ${ }^{6}$.

The newness of the information presented in the reason clause makes either because or for proper choices, with because being more fitting since the context is not very formal. However, the high degree of formality can make both because and for suitable choices. Consider:

(25) ... It was forced to withdraw two drugs from the States this year because they failed to meet US standards. This virtually halved six months profits to just 40.4. (BNC).

In Example (25) above, both because and for can be appropriate, with because being the better choice as it lends more strength to the cause, i.e., 'failing to meet US standards.' Observe that the casual marker because occurs in the second part of the sentence to explain why the action took place. That is, it introduces the important piece of information, which makes it the most felicitous of the four synonymous conjunctions in the study. Its occurrence in the second part, to introduce important information, coincides with Janeček (2013) findings that the subordinating conjunctions because and for tend to occur in the second part of the sentence, as they are associated with new information:

(26) I like basketball because it is a fast game.

(27) People must eat healthy food for it builds a strong body.

It is true that subordinating clauses introduce old information, yet here the subordinating clause conveys relatively important information, whose importance is perhaps equal to the new information conveyed in the main clause. Indeed, the reason introduced by the subordinating clause can be so crucial that it gains power, which supersedes the new information offered in the main clause.

Syntactically speaking, since and as occur both at the beginning and in the middle of sentences because they introduce given information, as in the examples above. Placing since at the beginning of a sentence makes it interchangeable with because more than with any of the other two causal conjunctions, as and for:

(28) ... Since I, without the benefit of tax relief, am paying as much as I ... (BNC).

(29) ... will not rest until a cure has been found. Which is marvelous news. Since it presumably means we will not for some time to come be seeing her again. (BNC). 
The following is one more example that supports the claim that the strength of the reason or the importance of the information it conveys may call for the use of because or for more than since and as.

(30) The premature release of these plans was a source of embarrassment and irritation to ministers as it might stir up greater opposition to what they wanted to do. (BNC)

In this instance, the modal 'might' conveys a sense of uncertainty, i.e., the release of the plans might stir opposition, but it might not. Therefore, the use of as tends to be more fitting than because or for, but this does not categorically rule out the possible use of because and for with this type of modality.

\subsubsection{Syntactic Constraints}

Another major determining principle contributing to the use of one but not the other synonymous expressions in the study is syntactic constraints. Recall that in the example:

(31) Are you mad at me because/* for $/ *$ since/*as I left the lights on all night? (BNC)

The preference of because over its synonymous counterparts is based on contextual considerations, since the context here is that of informal/spontaneous conversation. However, in the following example, only because is appropriate due to a syntactic constraint:

(32) Because $/{ }^{*}$ For $/{ }^{*} \mathrm{As} /{ }^{*}$ Since of bad weather, they could not transport by sea the small stones they required. (BNC)

In this example, the only possible alternative is because, which functions as part of a complex preposition "because of". The other counterparts are completely inappropriate, as they require a complete clause. In the example here, what comes after the causal conjunctions is merely a noun phrase, i.e., 'bad weather.'

The following are more examples, which show that because is not interchangeable with any of the other three subordinating conjunctions when it is followed by the preposition "of" as part of a prepositional phrase.

(33) ... she explained, could not get her back to Sandringham that early December night because of bad weather. Could she stay? Nobody, even if they had wanted ... (BNC).

(34) Martens, a German orthopedic surgeon, damaged his foot in a skiing accident. Because of this discomfort, he set about developing an air-cushioned sole with his engineer friend Herbert. (BNC).

After the construction $i t /$ this + be, namely a cleft sentence, none of "because's" synonyms can replace it. Consider:

(35) ... shrugs: 'I have got a clue.' I suppose it's because I've got a naughty face.' (BNC).

(36) The bank declined to grant him any loan despite his many trials. This is because/*since/* for $/{ }^{*}$ as the bank does not think his salary is enough to pay back the loan. (BNC)

In these examples, the conjunction because comes as part of the clause that functions as the complement of the verb "to be"- "... it's because I've got a naughty face," and "this is because the bank ..." - -a syntactic constraint that legitimizes the use of because rather than any of its counterparts, as indicated above. However, if we paraphrase Example (36), for instance, to become:

(37) The bank declined to grant him any loan despite his many trials because/for/since?/as? it does not think his salary is enough to pay back the loan.

Then because, for and, to a lesser degree, since become acceptable, though because sounds the most fitting as it tends to lend more strength to the reason which constitutes the important piece of information in the sentence.

If we paraphrase this example to start with the cause, the conjunction for will not be appropriate. Consider: 
(38) Because /Since/? As/*For the bank does not think his salary is enough to pay pack, he was not granted any loan despite his many trials.

Although as does not sound completely fitting, for reasons discussed above, the only viable reason for the unacceptability of for in this instance is its position. Our data did not reveal any causal for in the beginning of a sentence. It seems that it is not appropriate to start a sentence with for when the first clause it introduces indicates a reason and the second implies a result. The following examples illustrate this point further:

(39) He did not come to the meeting because/ for he was sick ${ }^{7}$

(40) Because $/{ }^{*}$ for he was sick, he did not come to the meeting.

The data also reveal that none of because's counterparts replaces it in statements where 'not only' is used, as in the following example:

(41) This MSc programme is unique not only because of its structure and teaching approach but also because of its student diversity, which makes the learning experience truly exceptional ${ }^{8}$

In this example, none of the three synonyms of because can replace it.

An additional restriction that does not allow the replacement of because by its three counterparts is when it starts an answer to a question. Consider:

(42) A: Why?

B: Because I'll still be covering for John. (BNC)

None of the three synonyms in the study can replace because in this example.

The above examples, 31-42, show that the functional use of the subordinating conjunctions varies. While two conjunctions may serve the same function, (e.g., because and for), they differ in syntactic usage. From a semantic point of view, both because and for may be used to provide new information through explaining a reason or purpose; however, they are different in that, while the because-clause can come in the initial and final position, the for-clause cannot come at the beginning.

(43) A: He went to school early because he wanted to practice ${ }^{9}$

B: Because he wanted to practice, he went to school early.

and

(44) A: He praised her as much as he could and gave alms in her name to the poor, for he was also generous. (BNC)

B: * For he was also generous, he praised her as much as he could and gave alms in her name to the poor.

It is noteworthy that the syntactic differences and constraints stated above are, by and large, well known, and they were not presented as new findings based on our corpus investigation. The purpose is to highlight the importance of such syntactic details for learners of English as a second language who should be familiarized with the role played by syntax in determining the use of a causative marker rather than its synonymous counterparts.

7 Available online: Introduction to Linguistics I English Morphosyntax. In http://jogja-morphosyntax.blogspot.com/2007/08/ complex-sentence.html (accessed on 10 August 2019).

8 Available online: MSc in Economics for Development. In https://www.ox.ac.uk/admissions/graduate/courses/msc-economicsdevelopment?wssl=1 (accessed on 28 July 2019).

9 Available online: Practise Hard (1)? In https://www.englishforums.com/English/PractiseHard1/khxmn/post.htm (accessed on 22 July 2019). 


\subsubsection{Degree of Formality and Lexical Density of the Utterance}

Another determining factor that governs the use of one of the four subordinating words rather than its synonymous counterparts is the degree of formality and lexical density of the utterance. The following example illustrates this characteristic.

(45) Are you mad at me because/? since/*for/*as I left the lights on all night? (BNC)

In this example, for, since and as are not very appropriate as they imply, among other things, a high degree of formality while the context here is one of an informal/spontaneous conversational exchange. The expression 'mad at me' is an informal one that shows that the question was uttered in an informal conversation, probably between family members. On the other hand, in a lexically dense, formal style, synonyms of because are acceptable and, in some cases, tend to be more fitting than because. Therefore, it is the pragmatic use of language represented in the context of situation-whether formal or informal - that was responsible for the choice of one particular conjunction but not the others. The use of for, for instance, is very felicitous in the following example.

(46) It is received with fear; for it threatens that comforting security and certainty which hitherto have shaped our action. (BNC).

The formal tone in this example, which is observed from the use of fairly loaded lexical items, namely 'fear' and 'threatens', makes because or for fitting choices, with for being a better choice given the high degree of formality that characterizes the sentence. That is, for is a very legitimate choice here as it adds to the formality of the utterance. Being associated with formal contexts, for, as a causative marker, is not found much in conversational style. The following are more examples that show that for is not used as often in a conversational style, but rather in formal discourse.

(47) I need to go to bed now because/? for I am tired. ${ }^{10}$

(48) I went shopping this afternoon because/? for I needed some groceries.

(49) [His] thoughts on the subject are worth quoting in full for he manages to incorporate a good quota of folk devils in his account. (BNC)

(50) My brother at length has given his consent that you should come and live with me. Therefore, get yourself ready; for I shall take you along with me now in my coach. (BNC)

In the first two instances, for sounds a little unfitting, since the context is that of small, ordinary, daily routine exchanges, and therefore, because sounds more felicitous. However, in examples (49) and (50) for sounds very fitting, as the context is very formal. The lexical density in both examples is quite high, with virtually none of the lexical items repeating themselves in both sentences.

To summarize, examples 45-50 above show that choice of one rather than the other causal conjunctions is not necessarily and exclusively based on purely theoretical/syntactic considerations, but also on metatheoretical aspects of sociolinguistic nature, i.e., formal vs. informal use. Such narrow distinctions between the different uses and functions of the four conjunctions are of considerable importance to language users in different disciplines, since language in use lies in the core of pragmatics, semantics, sociolinguistics, applied linguistics, discourse analysis, contrastive analysis, and translation studies. This renders the "degree of formality" indicator a significant variable in the choice of a particular conjunction against others. Such theorising is consistent with the principles and basic tenets of the philosophy of language.

\section{Conclusions and Implications}

In view of the preceding analysis, we conclude that the four subordinating causal conjunctions are synonymous and replace one another in varying degrees, but they are definitely not interchangeable.

10 Available online: http://beth-bfrank.blogspot.com. 
The degree of variation in the selection of one but not the other(s) is based on syntactic, semantic, and/or contextual and metalinguistic considerations. That is, the findings of the study show that the determining elements that legitimize the use of one of the subordinating conjunctions in the study rather than its counterparts include syntactic constraints, degrees of the importance of the information that the conjunction introduces, degrees of formality of the register, lexical density of the utterance that contains the conjunctions, etc.

Syntactically speaking, the conjunction because proved to be the strongest of all, as it is characterized with the structural mobility to occupy different positions (i.e., before or after the main clause) and in formal or informal discourse. Another syntactic characteristic of because which distinguishes it from all other three causative conjunctions is its grammatical word class as a conjunction. That is, since and as can be classified as adverbs, prepositions, or conjunctions. For has a double function; it can serve as a preposition-and this is the primary function it serves, as our data show-and a conjunction. In other words, since because has one part of speech designation while its synonymous counterparts have multiple non-causal designations, because can be an appropriate choice in most contexts. However, as discussed above, certain contextual, semantic and or pragmatic considerations can make the other causal subordinators more appropriate.

By invoking the semantic level of language, we notice that the interpretation of subordinating conjunctions depends primarily on context or reference, which identifies the relationship between language and the real world. Some words, expressions, including the subordinating conjunctions in question (because, since, for and as) may have multiple references. In this case, semantics is combined with logic.

To summarize, our findings show that there are certain considerations that make one choice more fitting than others. Such considerations include the information status of the utterance the causative marker introduces (old information vs. new or given/known information vs. new) and the nature of speech (i.e., formal written discourse vs. informal oral or written discourse). Other considerations include the strength or importance of the reason, genre, position of the causal marker (i.e., front or middle of the sentence), as well as syntactic constraints, such as using an NP rather than a clause after the causal marker, etc.

The following table (Table 1) summarizes the major features that tend to play a role in determining which synonym to use.

Table 1. Features determining the use of because, as, for and since.

\begin{tabular}{lcccc}
\hline \multirow{2}{*}{ Features } & \multicolumn{3}{c}{ Causal Linkers } \\
\cline { 2 - 5 } & because & as & for & since \\
\hline Non-causal use & - & + & + & + \\
Important reason introduced by the linker & + & - & + & - \\
High degree of formality & + & $-(+)$ & + & $-(+)$ \\
High lexical density & + & - & + & - \\
Given/known information introduced by the linker & + & + & $-(+)$ & + \\
Position in the sentence (in the front) & + & + & - & + \\
NP (not a clause) following the causal linker & + & - & - & - \\
Complement to verb (to be) & + & - & - & - \\
Response to a question & + & - & - & - \\
\hline
\end{tabular}

The plus sign indicates the normal use and the sign in parentheses indicates scarce possibility.

Our findings have shown that the proper use of subordinating conjunctions in discourse reflects knowledge of the rules of grammar. However, this very aspect of knowledge falls short of fully explaining why the four subordinating conjunctions under investigation cannot be used interchangeably. An integral and fundamental element to consider is the role of the epistemological nature of knowledge, which contributes significantly to a better understanding of the nature of this intricate relationship. This kind of knowledge enables language users to provide logical, rational, and sound arguments 
based on the truth of a proposition when subordinating conjunctions are involved. An interpretation of the communicative functions of causal conjunctions of the type discussed in this paper requires a good knowledge of the relationship between cause and effect, sense, logic, and meaning. Further, it presupposes prior knowledge of the rules of proper usage to render cohesive and coherent texts. It also requires an acquisition of cognitive skills, which show a person's readiness to learn and to apply knowledge that reflects a true understanding of the interdisciplinary nature of knowledge. Total dependence on overt surface structure synonymy may be misleading. More often than not, lack of familiarity with the rules of proper pragmatic, semantic, and discourse structure will render the speech act, with its locutionary, illocutionary, and perlocutionary effects, incomprehensible and confusing. It is for these reasons that context-based interpretation of subordinating conjunctions should be linked to the epistemological nature of knowledge.

In view of the above, it is very important that further research be conducted with extra emphasis on the use of causal subordinating conjunctions, both in the teaching and in writing of EFL and translation studies textbooks.

Author Contributions: Conceptualization, A.T.S. and S.A.-S.; methodology, A.T.S.; formal analysis, A.T.S. and S.A.-S.; investigation, A.T.S. and S.A.-S.; resources, A.T.S. and S.A.-S.; writing-original draft preparation, A.T.S. and S.A.-S.; writing-review and editing, A.T.S. and S.A.-S.; visualization, A.T.S. and S.A.-S.; supervision, A.T.S. and S.A.-S.; project administration, A.T.S. All authors have read and agreed to the published version of the manuscript.

Funding: This research received no external funding.

Conflicts of Interest: The authors declare no conflict of interest.

\section{References}

Biber, Douglas, Suzan Conrad, and Geoffrey Leech. 2002. Longman Student Grammar of Spoken and Written English. Essex: Longman.

Blackburn, Simon. 2017. Philosophy of Language. Available online: https://www.britannica.com/topic/philosophyof-language (accessed on 12 July 2019).

British National Corpus. 2000. World Edition. The Humanities Computing Unit of Oxford University. Oxford: University of Oxford.

Ford, Cecilia E., and Junko Mori. 1993. Causal Markers in Japanese and English Conversations: A Cross-linguistic Study of Interactional Grammar. Pragmatics 4: 31-61. [CrossRef]

Guillaume, Bénédicte. 2018. Looking for the Causal Values of as and since in Large Corpora, and How These Values Compare with Each Other. CORPUS 18: 1-25.

Hurford, James, Bernard Heasley, and Michael Smith. 2007. Semantics: A Course Book, 2nd ed. Cambridge: Cambridge University Press.

Janeček, Michal. 2013. English Causal Conjunctions Since, As and For and Their Czech Translation Equivalents. České Budějovice: University of South Bohemia, Faculty of Education, Department of English.

Lyons, John. 1981. Language and Linguistics. Cambridge: Cambridge University Press.

Meier, Einar. 2001. Since You Mention It: A Contrastive Study of Causal Subordination in English and Norwegian. Ph.D. dissertation, University of Oslo, Oslo, Norway.

Mo, Junhua. 2015. A Contrastive Study of the Use of Causal Connectives by Chinese EFL Learners and English Native Speakers in Writing. Theory and Practice in Language Studies 5: 2426-32. [CrossRef]

Mulkar-Mehta, Rutu, Andrew S. Gordon, Jerry Hobbs, and Eduard Hovy. 2011. Causal Markers across Domains and Genres of Discourse. Paper presented at Sixth International Conference on Knowledge Capture (K-CAP '2011), Banff, AB, Canada, June 26-29.

Povolná, Renatá. 2012. Causal and Contrastive Discourse Markers in Novice Academic Writing. Brno Studies in English 38: 131-48. [CrossRef]

Prince, Ellen. 1981. Toward a taxonomy of given-New information. In Radical Pragmatics. Edited by Peter Cole. New York: Academic Press, pp. 223-53.

Riddle, Elizabeth. 1989. Issues in the Acquisition of Word Meaning: Transition expression. Paper presented at TESOL Convention, San Antonio, TX, USA, March 7-11; pp. 1-14. 
Saeed, Aziz. 2004. On the Notion of Familiarity and Arabic Discourse. International Journal of Arabic-English Studies 4: $121-40$.

Saeed, Aziz. 2014. Contextual Considerations in the Use of Synonymous Verbs: The Case of Cease, End, Finish and Stop. International Journal of Arabic-English Studies (IJAES) 15: 103120-336.

Saeed, Aziz, and Shehdeh Fareh. 2006. Some Contextual Considerations in the Use of Synonymous Verbs: The Case of Steal, Rob and Burglarize. Studia Anglica Posananiensia 42: 323-36.

Sinclair, John, ed. 1990. Collins Cobuild York English Usage: Helping Learners with Real English. 1990. (2000 impression). Beirut: Library du Liban Publishers.

Sinclair, Melinda. 1992. The Effects of Context on Utterance Interpretation: Some Questions and Some Answers. Stellenbosch Papers in Linguistics 25: 103-32. [CrossRef]

Wang, Juan. 2009. A Corpus-based Study on the Chinese Near-synonymous Verbs of Running. In Proceedings of the 21st North American Conference on Chinese Linguistics (NACCL). Bryan: Bryant University, vol. 2, pp. $399-416$.

Publisher's Note: MDPI stays neutral with regard to jurisdictional claims in published maps and institutional affiliations.

(C) 2020 by the authors. Licensee MDPI, Basel, Switzerland. This article is an open access article distributed under the terms and conditions of the Creative Commons Attribution (CC BY) license (http://creativecommons.org/licenses/by/4.0/). 